\title{
The vascular component of sodium salicylate ototoxicity in the guinea pig
}

\author{
Anne Didier ${ }^{\mathrm{a}}$, Josef M. Miller ${ }^{\mathrm{b}}$ and Alfred L. Nuttall ${ }^{\mathrm{b}}$ \\ ${ }^{a}$ Laboratoire de Neurophysiologie Sensorielle, Bat 404, Universite Claude Bernard, Villeurbaune, France and ${ }^{b}$ Kresge Hearing Research Institute, \\ University of Michigan, Ann Arbor, Michigan, USA
}

(Received 30 September 1992; Revision received 3 May 1993; Accepted 7 May 1993)

\begin{abstract}
Drugs of the salicylate family (aspirin-like drugs) are reversibly ototoxic. Electrophysiologic and ultrastructural evidence suggests an impairment of the sensory hair cells of the cochlea following salicylate treatment. In addition, since these drugs can cause vasoconstriction, the ototoxicity of salicylates may also involve an impairment of the blood circulation in inner ear. However, a vascular hypothesis of salicylate toxicity has not received much attention. In the current study, we simultaneously measured cochlear blood flow (by laser Doppler flowmetry) and the sound-evoked potentials from the round window. Sodium salicylate caused a decrease in cochlear blood flow that appeared within 30 min following an intramuscular injection of a low dose of sodium salicylate $(100 \mathrm{mg} / \mathrm{kg})$. This sodium salicylate dose did not cause a change in auditory sensitivity. For higher doses $(200 \mathrm{mg} / \mathrm{kg}$ and $300 \mathrm{mg} / \mathrm{kg}$ ), both cochlear blood flow and auditory sensitivity were affected. The 300 $\mathrm{mg} / \mathrm{kg}$ dosc decreased blood flow by about $25 \%$ and elevated compound action potential thresholds by 10 to $25 \mathrm{~dB}$ for high frequencies ( $\geq 8$ $\mathrm{kHz}$ ). Further experiments showed that salicylate-induced threshold shifts were significantly reduced for the mid-frequencies when cochlear blood flow is increased by the vasodilating drug hydralazine (negating the flow reduction caused by salicylate). These data indicate that in addition to the direct effect of systemically administered salicylate on neurosensory function a decreased blood flow contributes to the ototoxicity of salicylates.
\end{abstract}

Sodium salicylate; Laser doppler flowmetry; Cochlea; Guinea pig; Hydralazine; Topical drug application

\section{Introduction}

Aspirin, related salicylate compounds, and other anti-inflammatory drugs are often prescribed for prolonged use at medium to high doses in the treatment of arthritis and other conditions. These therapeutic doses, as well as accidental intoxications with salicylate, have been reported to cause reversible hearing impairments. Some characteristics of this ototoxicity have been well described but its mechanism is still unclear. Salicylates cause tinnitus and auditory threshold shifts affecting the whole range of frequencies but more strongly at the highest frequencies of audition (Myers and Bernstein, 1965; McCabe and Dey, 1965; Bernstein and Weiss, 1967; Ramsden et al., 1985). The adverse effects of salicylates on hearing are always totally reversible within 1 to 2 days following the last drug treatment (Myers and Bernstein, 1965; McCabe and Dey, 1965; Bernstein and Weiss, 1967; Ramsden et al., 1985). The effect of salicylates on the electrophysiology of the cochlea has also been studied in different animal models (guinea-pig: Puel et al., 1990; Cazals et al., 1988; McPherson and Miller, 1974; Mitchell et al., 1973;

Correspondence to: Alfred L. Nuttall, Kresge Hearing Research Institute, University of Michigan Medical Center, 1301 East Ann Street, Ann Arbor, MI 48109-0506, USA. Fax: + 1 (313) 764-0014. squirrel monkey: Myers and Bernstein, 1965; Cat: Silverstein et al., 1967; Evans and Borerwe, 1982; Stypulkowski, 1990; chinchilla: Deer and Hunter-Duvar, 1982). All these studies showed salicylate-induced cochlear sensitivity shifts similar to those found in human hearing, i.e., reduced sensitivity ranging from 5 to $40 \mathrm{~dB}$, depending on the dose and the species used. Salicylates were also found to reduce the amplitude of the whole cochlear nerve action potential (CAP) evoked by low intensity sounds (for the most recent data, see Puel et al., 1990, Stypulkowski, 1990).

The presence of salicylate-induced tinnitus in animals, similar to that found in human, has been strongly indicated by indirect observations (Evans and Borerwe, 1982; Jastreboff et al., 1988). It has also been observed that human spontaneous oto-emissions are suppressed and evoked oto-emissions are reduced by salicylates (McFadden and Plattsmier, 1984; Long and Tubis, 1988).

Salicylates reduce the amplitude of the whole cochlear nerve action potential evoked by low intensity sounds (Silverstein et al., 1967; Mitchell et al., 1973; McPherson and Miller, 1974; Cazals et al., 1988; Puel et al., 1990; Stypulkowski, 1990). However, the literature provides a more controversial picture of the effect of salicylates on the cochlear microphonic, which can show increase, decrease or no change (Stypulkowski, 1990; Mitchell et al., 1973; Shehata et al., 1991; Cazals 
et al., 1988; McPherson and Miller, 1974; Silverstein et al., 1967; Puel et al., 1990). It has also been observed that human oto-emissions are suppressed by salicylates (McFadden and Plattsmier, 1984; Long and Tubis, 1988).

Taken together, the data of the above studies strongly indicate that the outer hair cell is the target for the toxicity of salicylates. For example, in the study by Stypulkowski (1990) salicylate-induced changes in cochlear function was attributed to an increase in outer hair cell membrane conductance, interfering with the transduction process. Salicylate-induced increase in membrane conductance has been confirmed in isolated outer hair cells (Shehata et al., 1991). In contrast to the physiological evidence, many anatomical studies have failed to show a hair cell pathology following salicylate intoxication that could account for the electrophysiologic changes. Ultrastructural observations have generally revealed no anatomical alterations of the hair cells, even when a significant level of hearing loss was achieved (Myers and Bernstein, 1965; Deer and Hunter-Duvar, 1982; Crifo, 1975) but some ultrastructural studies show that salicylates may be able to alter the structure of the outer hair cell subsurface cisternae (Douek et al., 1983; Dieler et al., 1991).

In addition to a possible action on hair cells, salicylates have been proposed to cause metabolic disturbances in the cochlea. Anatomical observations on surface preparations of the stria vascularis have indicated a possible reduction in blood flow induced by salicylates (Hawkins, 1976; Perez de Moura, 1968). An autoradiographic study has demonstrated the presence of salicylates in the capillaries of the stria vascularis and the spiral ligament. Smaller amounts of salicylate also appeared, with some delay, in the perilymphatic and endolymphatic spaces and in the organ of Corti (Ishii et al., 1967). The proposal that salicylate targets vascular mechanisms derives from its inhibitory action on the synthesis of prostaglandins (Vane, 1971; Escoubet et al., 1985) and on its stimulatory effect in the production of leukotrienes (Jung et al., 1989; 1992). While the specific role of these metabolites in the cochlea is still largely unknown, among the prostaglandins (PGs), prostacyclin (PGI2) and PGE2 have been shown to be potent dilating agents in other systems (Moncada, 1982). The interaction of salicylate with epinephrine, a vasoconstrictive sympatho-mimetic (Cazals et al., 1988), also supports a vascular action of salicylate. Furthermore, excessive levels of leukotrienes could mediate a decreased cochlear blood flow (CBF) (Jung et al., 1991).

The goal of the present study was to test the vascular hypothesis of the ototoxicity of salicylates. In the guinea-pig, we measured the CBF using a laser Doppler flowmeter (LDF) following both systemic and topical (on the round window membrane) administration of sodium salicylate. We assessed the relationship of $\mathrm{CBF}$ changes to sensitivity loss in some experiments. The first portion of the study focused on the effects of sodium salicylate alone. In the second part, we investigated the dependency of cochlear physiology on CBF by measuring the vascular and physiological effects of a dilating agent, hydralazine, on the toxicity of sodium salicylate.

\section{Material and Methods}

\section{Animal preparation}

Pigmented guinea-pigs $(N=46)$, weighing $250-450$ $\mathrm{g}$, of either sex were used. They were anesthetized with sodium pentobarbital $(7.5 \mathrm{mg} / \mathrm{kg}$ ip) followed by Innovar-Vet $(0.2 \mathrm{ml} / \mathrm{kg}, \mathrm{im})$. Additional half doses were given every $2 \mathrm{~h}$ (sodium pentobarbital) or every hour (Innovar-Vet). The animals were kept at $38^{\circ} \mathrm{C}$ with a thermo-regulated heating pad. A tracheotomy was performed and the animals breathed freely through the tracheal tube. The head was secured in a head-holder heated to avoid cooling of the cochlea (Brown et al., 1983a). The left carotid artery was cannulated and the catheter (PE 50 tubing) connected to a pressure transducer so that the systemic blood pressure (BP) was monitored throughout the experiment. The right auditory bulla was exposed by a ventro-lateral approach. Care was taken to assure that the bulla opening was performed without noise trauma (Brown et al., 1983b).

\section{Electrophysiological recordings}

A Teflon-coated platinum electrode was placed on the round window membrane. Tone burst sound stimuli $(15 \mathrm{~ms}$ duration, $1 \mathrm{~ms}$ rise-fall time, $10 / \mathrm{sec})$ were produced by a $1 / 2$ " Brüel \& Kjaer microphone using a closed field sound speculum fitted into the ear canal. A $1 / 2$ " Brüel \& Kjaer probe microphone system monitored the sound level near the tympanic membrane. Thresholds for the compound action potential (CAP) were determined visually after averaging 256 tone bursts, at 2, 4, 8, 24 and $32 \mathrm{kHz}$. A threshold amplitude of $\mathrm{N}_{1}$ deflection of the CAP was approximately $1 \mu \mathrm{V}$. Isopotential cochlear microphonic (CM) curves $(1 \mu \mathrm{V}$ rms) were also taken, in response to continuous pure tones. Electrophysiological measurements were done before and $30,60,90$ and/or 120 min after the administration of sodium salicylate.

\section{Cochlear blood flow measurements}

The probe of a LDF (TSI Laserflow model 403, probe diameter $0.7 \mathrm{~mm}$ ) was placed over the lateral wall of first cochlear turn. The output of the LDF, as well as the systemic $B P$, were recorded on a chart recorder. The computed ratio of $C B F$ to $B P$, which we call $R$, was also recorded. $R$ allows the evaluation of 
the $\mathrm{CBF}$ changes not directly related to systemic BP changes. Changes in $\mathrm{CBF}, \mathrm{R}$, and $\mathrm{BP}$ were measured from the chart recordings at different time intervals following the administration of drugs. These intervals were variable (from 2 to $30 \mathrm{~min}$ ) depending on the experiment and are specified in the results. For each time-point, averages were calculated across animals within each group. Data are expressed as percentage change from a baseline determined from a 10 to $20 \mathrm{~min}$ period prior to application of the drug. Electrophysiological data and CBF data were usually obtained from the same animals. For technical reasons, for 3 cases in the $200 \mathrm{mg} / \mathrm{kg}$ group, only CBF was obtained and for one case in the $300 \mathrm{mg} / \mathrm{kg}$ group, only electrophysiology was obtained.

\section{Administrations of sodium salicylate alone}

Sodium salicylate, freshly dissolved in saline, was injected intramuscularly at doses of $100(N=3), 200$ $(N=7)$, or $300(N=6) \mathrm{mg} / \mathrm{kg}$. In three additional groups, $1 \mu l$ of sodium salicylate was applied topically on the round window membrane, in the manner used by Ohlsén et al., (1990) at freshly prepared concentrations of $100 \mathrm{mM}(N=3), 200 \mathrm{mM}(N=9)$, or 300 $(N=4) \mathrm{mM}$. For both systemic $(N=4)$ and topical $(N=4)$ experiments, control experiments were performed in which saline replaced sodium salicylate.

\section{Combined administration of sodium salicylate and hy- dralazine}

The administration of $300 \mathrm{mg} / \mathrm{kg}$ of sodium salicylate was combined with the topical application of hydralazine as follows: A first group (group SH) $(N=5)$ received the intramuscular injection of sodium salicylate followed $30 \mathrm{~min}$ later by the topical application of $1 \mu 1$ of hydralazine solution at the concentration of 20 $\mathrm{mg} / \mathrm{ml}$. A second group (group HS) $(N=5)$ received the application of hydralazine followed $30 \mathrm{~min}$ later by the injection of sodium salicylate. In a third group $(N=4)$, we applied only hydralazine (group H). A group $S$ was constituted of the guinea-pigs that received $300 \mathrm{mg} / \mathrm{kg}$ of sodium salicylate in the first part of the study. CBF was monitored continuously, and evoked potentials were measured before administration of any drug and $2 \mathrm{~h}$ following the injection of sodium salicylate in group $\mathrm{S}, \mathrm{SH}$, and $\mathrm{HS}$ or $2 \mathrm{~h}$ following the application of hydralazine in group $\mathrm{H}$.

\section{Results}

\section{Effect of sodium salicylate by systemic administration}

The intramuscular administration of sodium salicylate caused a dose-dependent decrease in CBF. During the first half hour following the injection of the highest dose, it fell by $25 \%$. In contrast, BP increased (10\%)

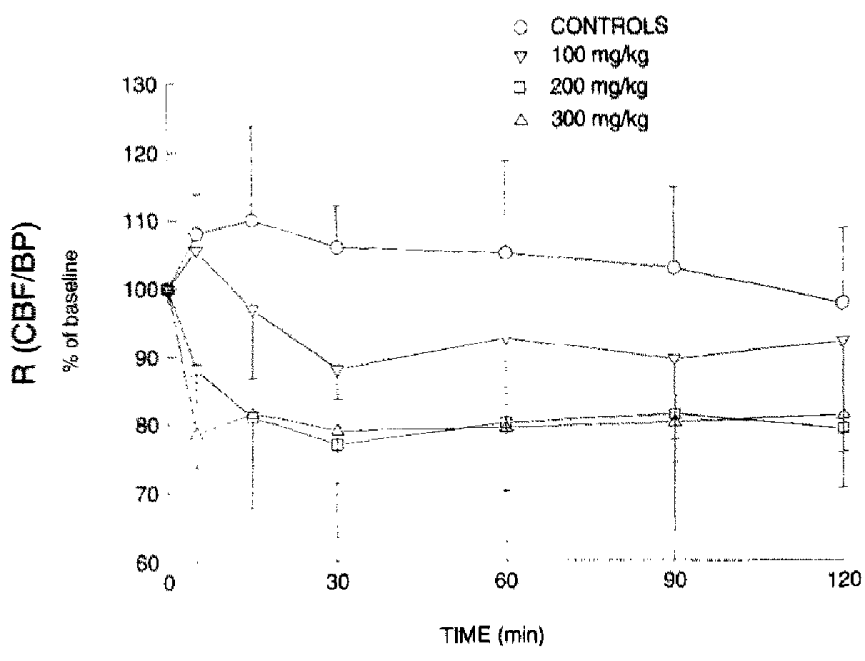

Fig. 1. The changes in the ratio of CBF to BP (R) expressed as percent of baseline following systemic im injections of saline or sodium salicylate at three different dose levels.

immediately following the injection, returned to baseline by 10 to $15 \mathrm{~min}$ post injection, and continued a very slow decline to $80 \%$ of the pre-drug value. As a result of the combined $\mathrm{CBF}$ and $\mathrm{BP}$ changes, $\mathrm{R}$ decreased but stabilized at $90 \%$ of the initial value by 30 min following the injection of $100 \mathrm{mg} / \mathrm{kg}$ (Fig. 1). For the higher doses, (200 and $300 \mathrm{mg} / \mathrm{kg}$ ), the decrease in $\mathrm{R}$ stabilized at a level of $75 \%$ of its initial level. Both the $200 \mathrm{mg} / \mathrm{kg}$ and $300 \mathrm{mg} / \mathrm{kg}$ dose produced the same $R$ reduction and $R$ did not show recovery by 120 min following any of the salicylate doses (Fig. 1).

The CAP threshold shifts associated with the administration of sodium salicylate are shown in Fig. 2. The lowest dose $(100 \mathrm{mg} / \mathrm{kg})$ did not produce any signiffcant sensitivity change. Following 200 and $300 \mathrm{mg} / \mathrm{kg}$, changes in sensitivity resemble those described in the literature. The high frequencies (above $8 \mathrm{kHz}$ ) showed

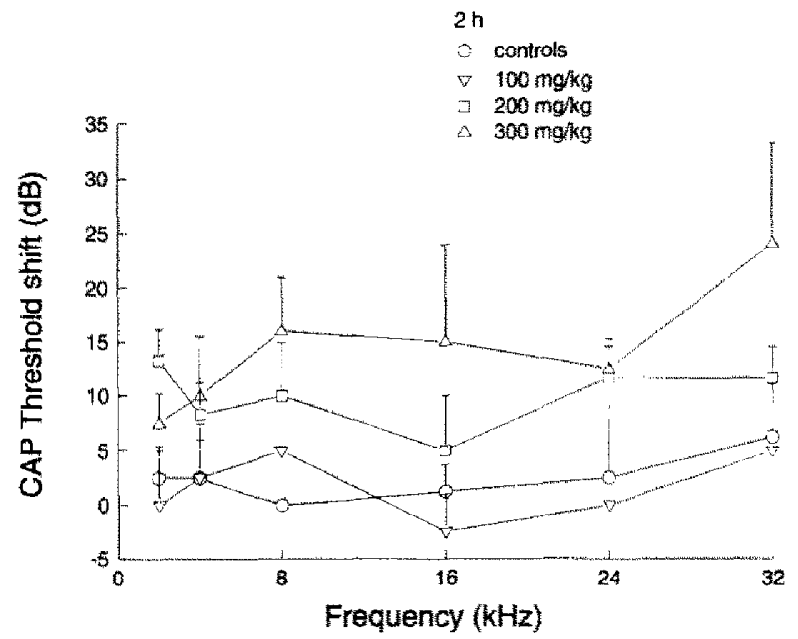

Fig. 2. Compound action potential threshold shifts induced $2 \mathrm{~h}$ after the im administration of sodium salicylate at three dose levels. 


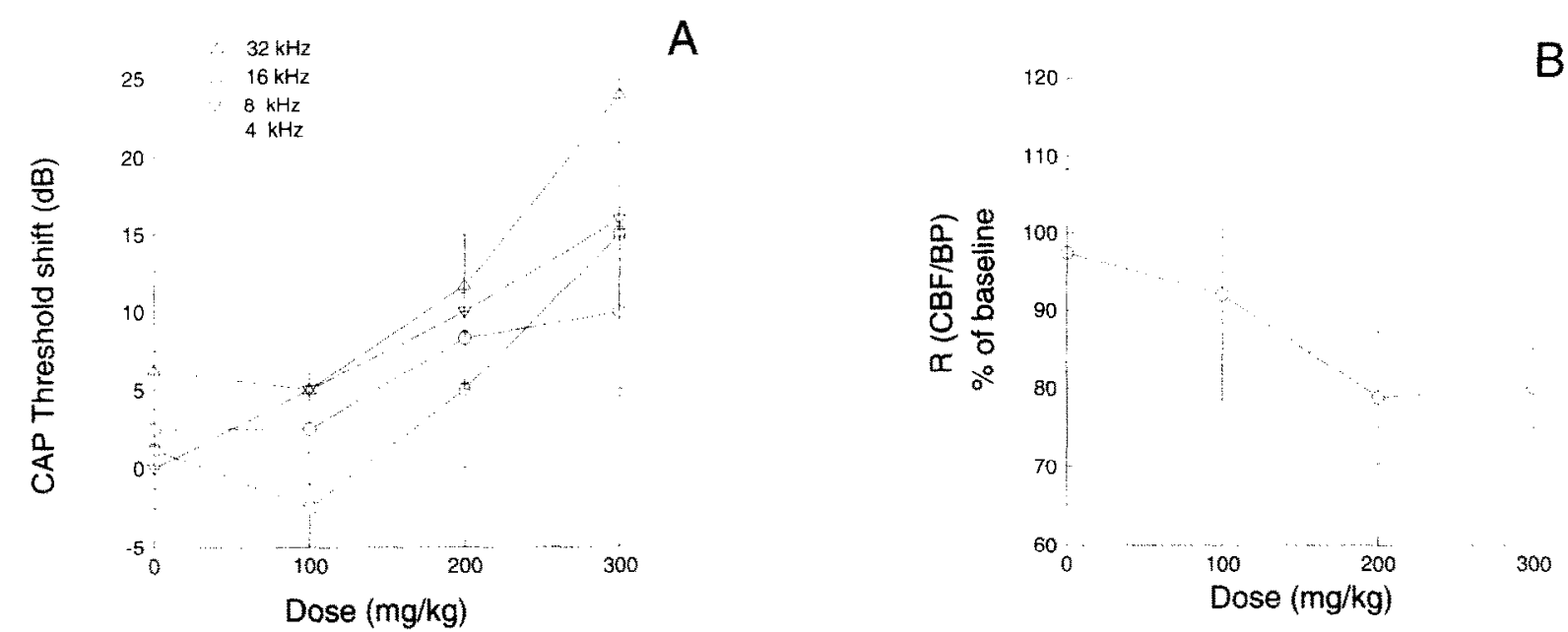

Fig. 3. (A) Dose/threshold shifts curves at $4,8,16$, and $32 \mathrm{kHz}$ following a $300 \mathrm{mg} / \mathrm{kg}$ dose of sodium salicylate. (B) Dose/R decrease curve. Same conditions as in $\mathrm{A}$.

a greater susceptability to sodium salicylate than the lower frequencies. After $1 \mathrm{~h}$, only the highest dose (300 $\mathrm{mg} / \mathrm{kg}$ ) produced a significant threshold shift (data not shown). Two $h$ after the injection (Fig. 2), the shift reached a level of $16 \pm 5 \mathrm{~dB}$ at $8 \mathrm{kHz}$ and $24 \pm 9 \mathrm{~dB}$ at $32 \mathrm{kHz}$ for a $300 \mathrm{mg} / \mathrm{kg}$ dose.

Table I shows the averaged changes in $\mathrm{CM} 2 \mathrm{~h}$ post injection. No clear changes are seen, although a trend toward a decrease in $\mathrm{CM}$ (i.e., increased sound level for $1 \mu \mathrm{V}$ response) and increased variability are observed in the group that received $300 \mathrm{mg} / \mathrm{kg}$ of sodium salicylate compared to the control group.

The input/output functions for CAP taken for a 16 $\mathrm{kHz}$ tone following $300 \mathrm{mg} / \mathrm{kg}$ of sodium salicylate showed a low intensity stimulation shift. The CAP latency was found consistently increased following 300 $\mathrm{mg} / \mathrm{kg}$. The increase in latency was often greater for the low intensity of stimulation (data not shown).

\section{Dose-response relationships}

The dose response relationship for the threshold shifts measured $2 \mathrm{~h}$ following sodium salicylate at 8,16 , and $32 \mathrm{kHz}$ are shown on Fig. $3 \mathrm{~A}$. The $300 \mathrm{mg} / \mathrm{kg}$ dose induced threshold shifts larger than those induced by $200 \mathrm{mg} / \mathrm{kg}$ for all the frequencies tested. In contrast, the dose-response curve for the $\mathrm{R}$ response (Fig. 3B) appears to saturate for concentrations greater than $200 \mathrm{mg} / \mathrm{kg}$.

\section{Effect of sodium salicylate by topical administration}

Topically applied sodium salicylate in the concentration of $100 \mathrm{mM}$ did not induce a significant change in CAP or CBF. However, doses of $200 \mathrm{mM}$ and $300 \mathrm{mM}$ induced a decrease in $C B F$ while the $B P$ was unaffected (Fig. 4A and B show changes in the R). The decrease in CBF was approximately $10 \%$ for both doses and showed greater variability than for systemic
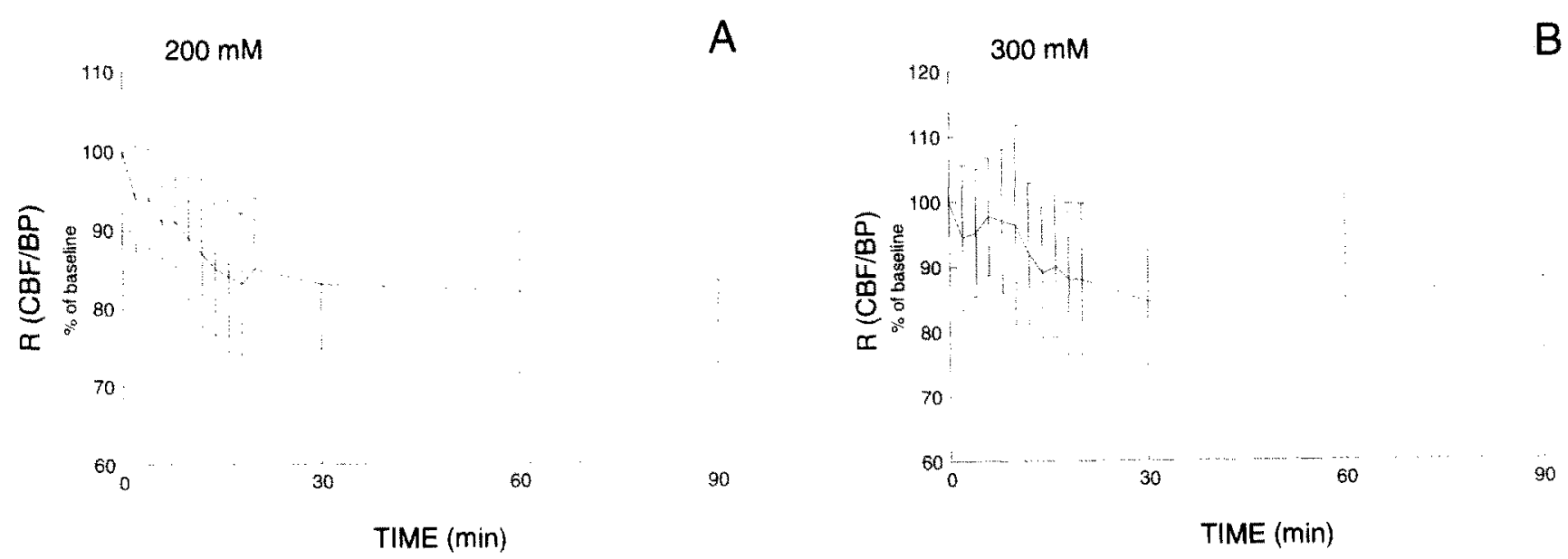

Fig. 4. $\mathrm{R}$ changes expressed as percent of baseline following topical application at the round window of $200 \mathrm{mM}(\mathrm{A})$ or $300 \mathrm{mM}(\mathrm{B}) \mathrm{sodium}$ salicylate. 

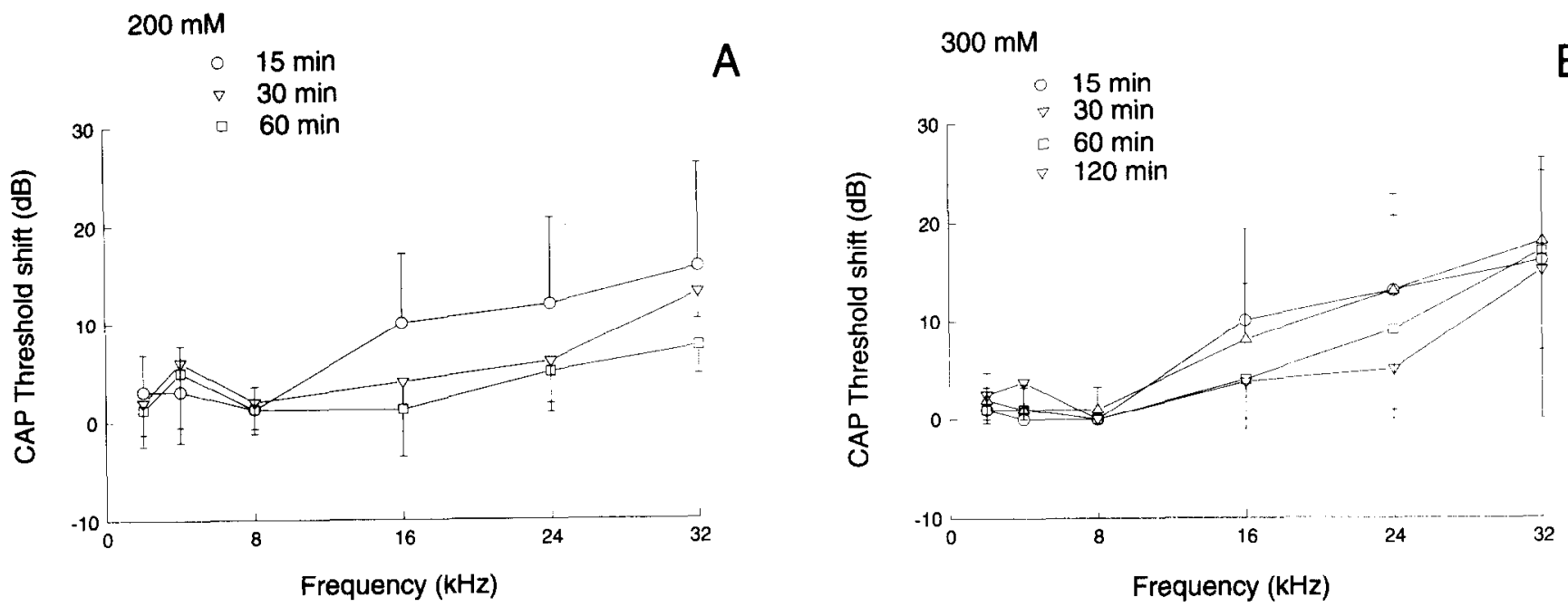

Fig. 5. Compound action potential threshold shifts induced by $200 \mathrm{mM}$ (A) and $300 \mathrm{mM}$ (B) sodium salicylate at 15, 30, 60, and 120 min following the application.

induced changes. The CAP loss induced by the topical applications of 200 and $300 \mathrm{mM}$ was confined to the high frequencies (16 kHz and above) and reached a maximum $15 \mathrm{~min}$ following the application (Figs. 5A and $5 \mathrm{~B})$. Recovery in auditory sensitivity was observed, starting in the first $1 / 2 \mathrm{~h}$ post application for the 200 $\mathrm{mM}$ dose and was completed in $1 \mathrm{~h}$. For the $300 \mathrm{mM}$ applications, thresholds remained elevated for $1 \mathrm{~h}$ and then recovered over the following hour. However, for $300 \mathrm{mg} / \mathrm{kg}$, the recovery was not complete within the

\section{TABLE I}

Mean sound level changes (in $\mathrm{dB}$ ) to produce $1 \mu \mathrm{V}$ rms of cochlear microphonics from pre-drug or pre-saline levels

\begin{tabular}{lccccccc}
\hline & \multicolumn{7}{c}{ Frequency (kHz) } \\
\cline { 2 - 8 } & 2 & 4 & 8 & 16 & 24 & 32 \\
\hline Systemic administration & & & & & & \\
Controls & -0.5 & -0.5 & -0.5 & -1.75 & -1.75 & -1.75 \\
SD & 1.3 & 1.3 & 0.6 & 1.5 & 3 & 2 \\
Group S (300 mg/kg) & 1.2 & 1.4 & $3.6 *$ & $6.2^{*}$ & 8 & 7.6 \\
SD & 3 & 2.7 & 2.8 & 5.6 & 8.2 & 6.3 \\
Group S-H & -1.5 & 0.5 & 1 & $1.5 *$ & 3.25 & 3.5 \\
SD & 3.7 & 3.7 & 2.3 & 1.3 & 3 & 4.2 \\
Group H-S & -4 & -1.5 & -0.25 & 3.5 & 2.75 & 4.25 \\
SD & 6.3 & 2.64 & 1.5 & 5.8 & 3.2 & 8.3 \\
Group H & -0.7 & 2.3 & 0.7 & 1.3 & 6 & 5.7 \\
SD & 0.6 & 2.9 & 1.15 & 3 & 4.3 & 3.8 \\
Topical administration & & & & & & \\
Controls & 2.5 & 0.4 & 1.6 & 2.8 & 0.75 & 2.75 \\
SD & 3.25 & 3.6 & 2 & 4.4 & 0.5 & 4.9 \\
300 mM & $-2 *$ & 0.25 & -1.5 & 0.25 & 1.25 & 5.5 \\
SD & 2.2 & 3.8 & 2 & 1.5 & 1.5 & 2.6 \\
\hline
\end{tabular}

Measurements were taken $2 \mathrm{~h}$ post systemic administrations and 15 min post topical applications. (* indicates statistical significance at a $P$ level of 0.05 ). 2-hr observation period and a $10 \mathrm{~dB}$ loss remained at $32 \mathrm{kHz}$. No changes in CM were observed (Table I).

\section{Effect of hydralazine treatment}

CBF changes for the different treatment groups are shown in Fig. 6. Group $\mathrm{H}$ : Within 5 min following topical application of hydralazine, CBF increased slowly to about $100 \%$ of the baseline value at $1 \mathrm{~h}$ post administration. The increased $\mathrm{CBF}$ was maintained throughout the 2-hr observation period. Group SH: The initial decrease induced by sodium salicylate was similar to the decrease observed in group $S(300 \mathrm{mg} / \mathrm{kg}$ sodium salicylate alone) but then, following the topical application of hydralazine (at the $30 \mathrm{~min}$ time point), CBF incrcased as in group $H$. As a result, $1 \mathrm{~h}$ after the injection of sodium salicylate, $\mathrm{CBF}$ overall was overall

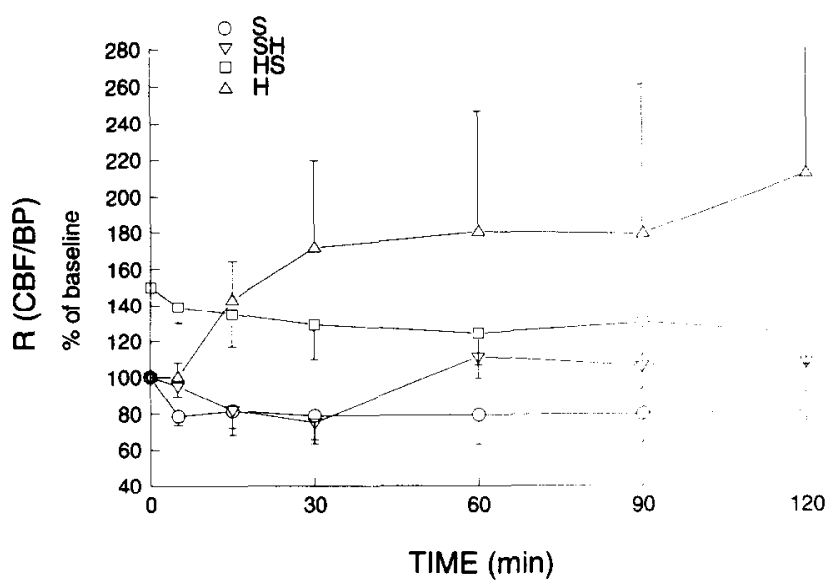

Fig. 6. $R$ changes induced by sodium salicylate (group $S$ ), hydralazine (group $\mathrm{H}$ ), and the combined treatment of hydralazine followed by salicylate (group HS) or salicylate followed by hydralazine (group $\mathrm{SH})$. 


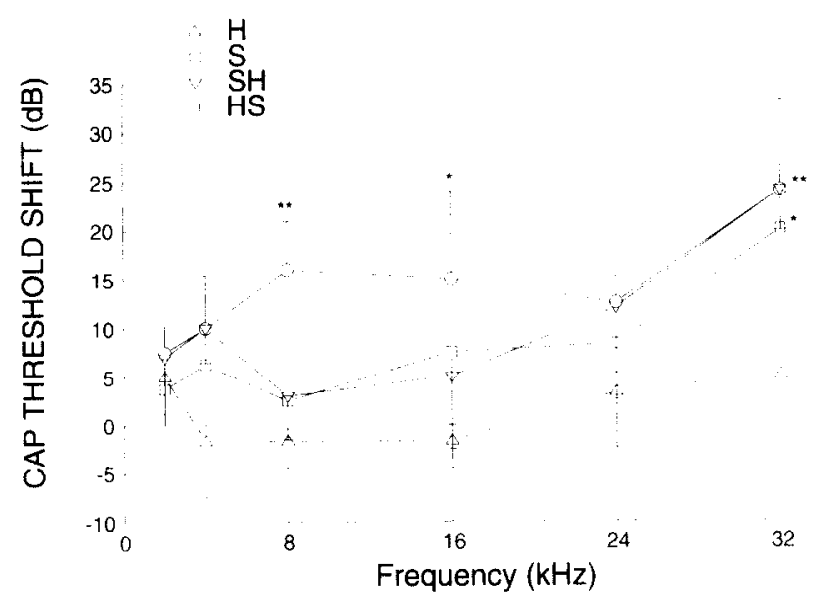

Fig. 7. Compound action potential threshold shifts $2 \mathrm{~h}$ after the administration of sodium salicylate. The difference was statistically significant as tested by unpaired two-tailed t-test with a $P$ value less than $0.05\left(^{*}\right)$ or less than $0.005\left(^{* *}\right)$. Same groups as in figure 6 .

increased by about $15 \%$ compared to the baseline value. Group HS: Pretreatment with hydralazine induced an increased CBF which is shown here at an initial level of $150 \%$. Following the administration of sodium salicylate, CBF decreased, stabilizing at about $30 \%$ above baseline value. Fig. 7 shows the threshold shifts induced in the different groups at various frequencies at $2 \mathrm{~h}$. In the control group (shown in Fig. 2), the sensitivity was not affected. The same was true for group $\mathrm{H}$ which did not show significant changes in sensitivity. The shift at 8 and $16 \mathrm{kHz}$ in group $\mathrm{S}$ was larger than the shift in group SH and HS. The difference was statistically significant as tested by unpaired two-tailed t-test with a $P$ value less than $0.05(*)$ or less than $0.005(* *)$.

\section{Discussion}

Use of the LDF allowed us to make a continuous measurement of the CBF during the administration of sodium salicylate. The contribution of the different cochlear vascular beds to the LDF output, however, is not known. Theoretically, the major contribution to the output of a LDF probe placed over the bony wall of the cochlea is made by the lateral wall vessels, a minor contribution coming from the basilar membrane or modiolar vessels (Miller and Nuttall, 1990). Comparison of the LDF output with measures of the total CBF obtained from the microspheres technique indicated that the LDF output underestimates but correlates well with the CBF increase induced by hemodilution as measured with microspheres (Nuttall et al., 1988).

The results of the current study clearly demonstrate a decrease in CBF following the administration of sodium salicylate. This supports the hypothesis of a vascular action of salicylate in the cochlea. One possible mechanism leading to a decreased CBF involves the blocking effect of salicylates on the production of PGs in the cochlea. The PGs synthesized in the endothelium of the lateral cochlear wall are PGI2 and PGE2. These are vasodilating substances. Escoubet et al. (1985) found that the production of PGs was abolished in the cochlea $30 \mathrm{~min}$ following the administration of a dose of $350 \mathrm{mg} / \mathrm{kg}$ of aspirin. Thus, the time-course of the decrease observed in the current study is very consistent with the actual blockade of $\mathrm{PG}$ synthesis by salicylates. Jung et al. (1992) has also shown that PGs are reduced while the leukotrienes (vasoconstrictive substances) are simultaneously increased.

In the current study, topical application of sodium salicylate led to a smaller and less consistent effect on the CBF than the systemic administrations. This may imply that the effect of salicylates on the cochlear vessels is dependent on the route followed by the drug. Given systemically, the drug most likely reaches the cochlea by diffusion from the blood vessels (Jastreboff et al., 1988). Ishii et al. (1967) were able to show by autoradiography that sodium salicylate is first incorporated into the walls of stria vascularis blood vessels before reaching the perilymphatic and endolymphatic spaces. Onc can hypothesize that, when given topically, sodium salicylate induced a smaller effect because the concentration in the area of the blood vessels did not reach a sufficiently high level. Jung et al. (1991) obtained an apparently larger CBF decrease for round window applied salicylate (150 $\mu \mathrm{g}$ vs $48 \mu \mathrm{g}$ maximum dose delivered in $1 \mu \mathrm{l}$ to the round window in the current study), but no dose-response data were given to assess whether the response was maximal. It is consistent that our data, obtained after systemic administration, show that the decrease in CBF is the earlier manifestation of the drug since it is seen in the blood vessels that are reached first by the drug.

The changes in CAP sensitivity and latency presented in this study are quite comparable to the earlier literature on the subject. In our data (Table I), CM was largely unchanged by systemically or topically applied salicylate or hydralazine. There was a trend toward decreased $\mathrm{CM}$ for the systemically given salicylate (without hydralazine), which was statistically significant for the two mid-frequencies 8 and $16 \mathrm{kHz}$. Puel et al. $(1989,1990)$ perfused salicylate into the cochlea and found either no effect or dccrcased CM. Stypulkowski (1990), in contrast, showed increased levels of CM for systemic (IV) injection of salicylate in the cat. The variability among these studies could be due to route of administration and species differences.

In our data, the significant reduction in CAP is associated, in part, with changes in CBF, which could imply a metabolic component in the salicylate effect. 
This hypothesis is consistent with the data showing that CAP is more susceptible than CM or the endocochlear potential (EP) to hypoxia (Brown et al., 1983b), and with the slight decrease in EP induced by salicylates (Puel et al., 1990; Stypulkowski, 1990).

To help clarify the contribution of a vascular component of sodium salicylate toxicity, we conducted the set of experiments in which CBF was increased in the presence of hydralazine thereby partly or fully negating the CBF reduction by salicylate. Hydralazine is efficient in increasing CBF over long period of time (Ohlsén et al., 1990). In the current experiments, hydralazine at the concentration of $20 \mathrm{mg} / \mathrm{ml}$ does not alter cochlear sensitivity (however, higher doses have been reported to impair the sound-evoked responses of the cochlea (Ohlsén et al., 1993). It should be noted also that the increase in CBF induced by hydralazine does not 'improve' or cause hypersensitivity in the normal ear. Sodium salicylate-induced threshold shifts were reduced by the hydralazine treatment. When successively applied in the same animal, the effect of hydralazine as well as of sodium salicylate was of a similar magnitude and time course regardless of the protocol used (salicylate before hydralazine or hydralazine before salicylate). We conclude from this that there is no pharmacological interaction of the two drugs on their site of action on blood flow and that the higher CBF in hydralazine-treated animals could account for the reduction in sodium salicylate-induced loss in sensitivity. This result is of interest from a clinical viewpoint. It demonstrates in an animal model of vascular pathology, the efficacy of a vasodilating treatment.

Based on the dose-response curves for threshold shifts and change in CBF/BP (Figs. 1 and 2), we can conclude that a $10 \%$ decrease in $\mathrm{R}$, induced by a 100 $\mathrm{mg} / \mathrm{kg}$ dose, has no effect on the cochlear function. These figures also show that the dose relationship is different for changes in sensitivity and in CBF: CBF decrease saturates at $200 \mathrm{mg} / \mathrm{kg}$ while CAP thresholds continue to increase above $200 \mathrm{mg} / \mathrm{kg}$. This suggests that different mechanisms are involved, and one should not expect a close correlation between CBF changes and sensitivity changes.

However, taken together, our results indicate that the salicylate-induced decrease in CBF could be partly responsible for or potentiate the loss in sensitivity. Further studies, using specifically vasoactive drugs, should focus on assessing the causal relationship between a decreased CBF and impairment of cochlear function.

In the present experiments, the primary effect of hydralazine in reducing the salicylate-induced threshold shift is restricted to the mid-frequencies. The reason for this effect is not clear. High frequencies are known to be susceptible to surgical trauma and other factors. Thus, even if in the control group, the high frequencies are well preserved it is possible that an additive factor potentiates the salicylate toxicity at high frequencies.

\section{Summary}

This study demonstrates sodium salicylate-induced decreases in CBF that can occur without sensitivity changes (for low salicylate doses). Increasing CBF by an independent mechanism provides some protection to the cochlea from the adverse effect of sodium salicylate. We conclude then that the low CBF induced by salicylate is part of the toxic mechanism leading to salicylate-induced hearing loss. Thesc results would need to be taken into account in studies exploring the interactive mechanism of salicylates with other cochleotoxic agents, particularly with noise which has also been shown to influence CBF (Axelsson et al., 1987; Quirk et al., 1991; Thorne and Nuttall, 1987; Ryan, 1988).

\section{Acknowledgments}

This research was supported by funds from NIH research grant RO1-DC00105.

\section{References}

Axelsson, A. and Dengerink, H.A. (1987) The effect of noise on histological measures of the cochlear vasculature and red blood cells: a review. Hear. Res. 31, 183-193.

Bernstein, J.M. and Weiss, A.D. (1967) Further observations on salicylate ototoxicity. J. Laryngol. Otol. 81, 915-925.

Brown, M.C., Smith, D.I. and Nuttall, A.L. (1983a) The temperature dependency of neural and hair cell responses cvoked by high frequencies. J. Acoust. Soc. Am. 73, 1662-1670.

Brown, M.C., Nuttall, A.L., Masta, R.I. and Lawrence, M. (1983b) Cochlear inner hair cells: effects of transient asphyxia on intracellular potentials. Hear. Res. 9, 131-144.

Cazals, Y., Li, X.Q., Aurousseau, C. and Didier, A. (1988) Acute effects of noradrenaline related vasoactive agents on the ototoxicity of aspirin: An experimental study in the guinea-pig. Hear. Res. 36, 89-96.

Crifo, S. (1975) Aspirin ototoxicity in the guinea-pig. ORL 37, 27-34.

Deer, B.C. and Hunter-Duvar, I. (1982) Salicylate ototoxicity in the chinchilla: a behavioral and electron microscope study. J. Otolaryngol. 11, 4, 260-264.

Dieler, R., Shehata-Dieler, W.E. and Brownell, W.E. (1991) Concomitant salicylate-induced alterations of outer hair cell subsurface cisternae and electromotility. J. Neurocytol. 20, 8, 637-653.

Douek, E.E., Dodson, H.C. and Bannister, L.H. (1983) The effects of sodium salicylate on the cochlea of guinea-pigs. J. Otol. Laryngol. 93, 793-799.

Escoubet, B., Amsallem, P., Ferrary, E. and Tran Ba Huy, P. (1985) Prostaglandin synthesis by the cochlea of the guinea-pig. Influence of aspirin, gentamycin and acoustic stimulation. Prostaglandins 29, 4, 589-599. 
Evans, E.F. and Borenwe, T.A. (1982) Ototoxic effects of salicylates on the responses of single cochlear nerve fibers and on cochlear potentials. Br. J. Audiol. 16, 101-108.

Hawkins, J.E. (1976) Drug ototoxicity. In: W.D. Keidel and W.D. Neff (Eds.) Handbook of Sensory Physiology, Springer Verlag, Berlin, pp. 708-712.

Ishii, T., Bernstein, J.M. and Balogh, K. (1967) Distribution of tritium-labeled salicylate in the cochlea: an autoradiographic study. Ann. Otol. Rhinol. Laryngol. 76, 368-376.

Jastreboff, P.J., Brennan, J.F. and Sasaki, C.T. (1988) An animal model for tinnitus. Laryngoscope, 98, 280-286.

Jung, T.T.K., Miller, S.K., Perk, Y.M., Woo, H.Y. and Baer, W. (1989) Effect of non-steroidal antiinflammatory drugs on levels of lipoxygenase products in perilymph and hearing. Abstr. Assoc. Res. Otolaryngol. 118.

Jung, T.T.K., Hwang, A.L. and Miller, S.K. (1991) Effect of sodium salicylate and leukotriene blocker on cochlear blood flow. Abstr. Assoc. Res. Otolaryngol. 377.

Jung, T.T.K., Miller, S.K., Rozehnal, S., Woo, H.Y., Park, Y.M. and Baer, W. (1992) Effect of round window membrane aplication of salicylate and indomethacin on hearing and levels of arachidonic acid metabolites in perilymph. Acta Otolaryngol. (Stockh.) 493, $81-87$.

I ong, G.R. and Tubis, A. (1988) Modification of spontaneous and evoked otoacoustic emissions and associated psycho-acoustic microstructure by aspirin consumption. J. Acoust. Soc. Am. 84, 4, $1343-1353$.

McCabe, P.A. and Dey, F.L. (1965) The effects of aspirin upon auditory sensitivity. Ann. Otol. Rhinol. Laryngol. 74, 312-325.

McFadden, D. and Plattsmier, H.S. (1984) Aspirin abolishes spontaneous oto-acoustic emissions. J. Acoust. Soc. Am. 76, 443-448.

McPherson, D.L. and Miller, J.M. (1974) Choline salicylate: Effects on cochlear function. Arch. Otolaryngol. 99, 304-308.

Miller, J.M. and Nuttall, A.L. (1990) Cochlear Blood Flow. In: A.P. Shepherd and A. Oberg (Eds.), Laser Doppler Blood Flowmetry. Kluwer Academic Publishers, Norwell, MA.

Mitchell, C.. Brummett. R.. Himes, D. and Vernon, J. (1973) Electrophysiological study of the effect of sodium salicylate upon the cochlea. Arch. Otolaryngol. 98, 297-301.

Moncada, S. (1982) Prostacyclin and arterial wall biology. Artcriosclerosis 2, 193-207.

Myers, E.N. and Bernstein, J.M. (1965) Salicylate ototoxicity. A clinical and experimental study. Arch. Otolaryngol. 82, 483-493.

Nuttall, A.L., Hultcrantz, E., Larsen, H.C. and Angelborg, C. (1988)
Cochlear blood flow increases after systemic hemodilution: comparison of simultaneous laser Doppler flowmetry and radioactive microsphere measurements. Hear. Res. 34, 215-223.

Ohisén, A.K., Miller, J.M. and Nuttall, A.L. (1990) Enhancing cochlear blood flow: a survey of six vasodilating agents. Abstr. Assuc. Res. Otolaryngol. 353.

Ohlsén, A.K., Hultcrantz, E. and Engstrom, B. (1993) The effect of topical application of vasodilating agents on cochlear electrophysiology. Acta Otolaryngol, (Stockh.) 113, 55-61.

Perez de Moura, L.F. (1968) Salicylate ototoxicity. Arch. Otolaryngol. $8760-65$.

Puel, J.L., Bledsoe, S.C., Bobbin, R.p., Ceasar, G. and Fallon, M. (1989) Comparative actions of salicylate on the amphibian lateral line and guinea pig cochlea. Comp. Biochem. Phys. 93C, 73-80.

Puel, J.L., Bobbin, R.P. and Fallon, M. (1990) Salicylate, mefenamate, meclofenamate and quinine on cochlear potentials. Otolaryngol. Head Neck Surg. 102, 66-73.

Quirk, W.S., Avinash, G., Nuttall, A.L. and Miller, J.M. (1991) The influence of loud sound on red blood cell velocity and capillary diameter in the lateral wall of the guinea-pig cochlea. Abstr. Assoc. Res. Otolaryngol. 376.

Ramsden, R.T., Latif, A. and O'Malley, S. (1985) Electrocochleographic changes in acute salicylate overdosages. J. Laryngol. Otol. 99, 1269-1273

Ryan, A.F. (1988) Circulation of the inner ear: 11; The relationship between metabolism and blood flow in the cochlea. In: A.F. Jahn and J. Santos-Sacchi (Eds.), Physiology of the Ear, Raven Press, pp. $317-325$.

Shehata, W.E., Brownell, W.E. and Dieler, R. (1991) Effects of salicylate on shape, electromotility and membrane characteristics of isolated outer hair cells from guinea pig cochlea. Acta Otolaryngol. (Stockh.) 111, 707-718.

Silverstein, H., Bernstein, J.M. and Davies, D.G. (1967) Salicylate ototoxicity, a biochemical and electrophysiological study. Ann. Otol. Rhinol. Laryngol. 76, 118-128.

Stypulkowski, P.H. (1990) Mechanisms of salicylate ototoxicity. Hear. Res. 46, 113-146.

Thorne, P.R. and Nuttall, A.L. (1987) Laser Doppler measurements of cochlear blood flow during loud sound exposure in the guineapig. Hear. Res. 27, 1-10.

Vane, J.R. (1971) Inhibition of prostaglandins synthesis as a mechanism of action for aspirin-like drugs. Nature Rev. Biol. 231 , 232-235. 